\title{
Modeling the Fourth Dimension of Architectural Heritage: Enabling Processes for a Sustainable Conservation
}

\author{
Raissa Mammoli $^{1, *(D)}$, Chiara Mariotti ${ }^{2}$ (D) and Ramona Quattrini ${ }^{2}$ (D) \\ 1 Department of Architecture (DA), Alma Mater Studiorum, University of Bologna, 40136 Bologna, Italy \\ 2 Department of Construction, Civil Engineering and Architecture (DICEA), Università Politecnica delle \\ Marche, 60131 Ancona, Italy; chiara.mariotti@univpm.it (C.M.); r.quattrini@univpm.it (R.Q.) \\ * Correspondence: raissa.mammoli@unibo.it
}

Citation: Mammoli, R.; Mariotti, C.; Quattrini, R. Modeling the Fourth Dimension of Architectural Heritage: Enabling Processes for a Sustainable Conservation. Sustainability 2021, 13, 5173. https://doi.org/10.3390/ su13095173

Academic Editors: Francesca Di Turo and Marc A. Rosen

Received: 22 February 2021

Accepted: 27 April 2021

Published: 6 May 2021

Publisher's Note: MDPI stays neutral with regard to jurisdictional claims in published maps and institutional affiliations.

Copyright: (C) 2021 by the authors Licensee MDPI, Basel, Switzerland. This article is an open access article distributed under the terms and conditions of the Creative Commons Attribution (CC BY) license (https:/ / creativecommons.org/licenses/by/ $4.0 /)$.

\begin{abstract}
This study focuses on modeling the fourth dimension of historic architectures with an HBIM approach and special regard to stratigraphic analysis. The goal is to push the limits of current technology to understand the history of buildings, with impacts on protecting their authenticity; it is pursued with a practitioners-oriented methodology able to make aware models of their phases. The target audience are experts in the field of heritage conservation, while the outcome is to support long-term strategies for the sustainable management of heritage. Contents follow this structure: (1) Introduction: this section frames the benefits of affirming heritage's physical authenticity and managing risks; it clarifies assumptions and the research aim; (2) State of the Art: this highlights the topic relevance, which is not yet fully resolved, focusing on semantics, critical-interpretative data control, and on the automation of some crucial results; (3) Materials and Methods: this describes the integrated workflow, including the photogrammetric acquisition, modeling, and data enrichment, the semi-automatic Harris matrix construction, and the optimization of laser data; (4) Results: this presents the results of modelling stratigraphic units, enriching them with information according to a semantics coherent with the conservation process, to govern the temporal relations while automating key outputs; (5) Discussion: this section refines the implemented solutions and introduce future works.
\end{abstract}

Keywords: architectural heritage; HBIM; Harris matrix; sustainable conservation; authenticity

\section{Introduction}

\subsection{Cultural Background}

Today, digital technologies open up scenarios of great interest in the sustainable conservation of cultural heritage and provide enabling tools to adequately address some of the crucial problems that put heritage at risk. Over the last few years, in particular in Italy, such an issue has become extremely urgent, due to the theoretical and legislative need to make heritage management coherent, coordinated, and planned (Codice dei Beni Culturali e del Paesaggio, 42/2004, art. 29). As a matter of fact, a wide range of research has been centered on the experimentation of suitable digital tools, such as Heritage or Historic Building Information Modeling (HBIM). Most efforts have been geared towards the construction of well-informed, informable, and queryable models, which can support long-term processes of conservation of historic buildings and sites. Major challenges have been placed in the joint management of multiple dimensions of architectural heritage in the HBIM environment, such as parametric modeling (3D), time (4D), costs (5D), management (6D), sustainability (7D), and safety (8D).

Among all these dimensions [1,2], this paper focuses on modeling the fourth one, the time, by stressing the diachronic management of semantic contents in HBIM. The effort to incorporate semantically enriched information in the model is justified by the need to develop spatio-temporal databases capable of conveying and clearly showing how the 
building evolved over the time. This is a fundamental issue in the knowledge representation and ontologies management of high-value historical architecture, and in restoration and preventive conservation. As is known, the approach to an existing building always requires the chronological classification of its structures through stratigraphic analyses, which are usually represented by two-dimensional drawings that inevitably neglect the three-dimensional relationship between the parts. Furthermore, literature in this sector has repeatedly highlighted specific difficulties in creating the Harris matrix, which is the symbolic visualization of the building's formation/transformation process, and therefore one of the most significant outputs of this kind of analysis, especially in the case of architectures with complex spatial and volumetric structures. Hierarchically organizing data on historic building transformations while digitalizing and automating the representation of all evolutionary phases are objectives to achieve in order to renew the well-established methodology of architectural heritage investigation towards its protection. As conservation strategies move from hermeneutical processes enriched from knowledge building, each digital tool addressed to cultural heritage protection may not provide adequate knowledge representation [3]. For this reason, it is essential to consciously integrate the potential of new technologies in managing complex data systems with humanistic issues related to cultural heritage activities.

From a digital humanities perspective, modeling a 4D-aware HBIM can offer several benefits. On the one hand, it enriches the knowledge phase of the conservation process and contributes to affirming the physical and material authenticity of historic buildings. This is a vital issue if we consider that, over time, the concept of "authenticity" has registered a progressive shift from the physicality of cultural heritage towards increasingly conceptual domains-just consider the Burra Charter (1979), which proposed an alternative approach to the conservation matter that almost transcends the materiality of heritage (art. 1-2) [4]. On the other hand, it supports and improves heritage management strategies, which have been given increasing attention in recent years, as UNESCO's commitment to World Heritage Sites has demonstrated $[5,6]$. By modeling time, it is possible to acquire an indepth knowledge of building transformations, and thus help reduce heritage's exposure to risk-both extraordinary, such as an earthquake, since interfaces between diachronic structures are clear, and ordinary-thus supporting the implementation of preventive conservation plans.

\subsection{Assumptions and Aim}

The research chain combines the aims of two disciplines, the survey and restoration of architecture, by stressing the modeling of the fourth dimension of historic architectures with a semantic-enriched HBIM approach and special regard for stratigraphic analysis. The objective is to push the limits of current technology to understand the history of these buildings, with impacts on protecting their authenticity and managing their complexity. The final outcome is to implement a stratigraphic-informed 3D model capable of supporting long-term strategies for heritage's sustainable conservation and management.

The assumption of this research lies in the value of time, both as an essential coordinate for heritage interpretation in the present and as a crucial factor for heritage preservation in the future. Priority goals are as follows: to enrich the 3D model of an ancient building with chronological and stratigraphic data from direct and indirect analysis (e.g., study of materials, construction techniques, and historical sources) by using methods, jargons, and representation codes proper to the discipline of conservation, and to semi-automate the construction of the Harris matrix by facilitating the creation of complex but vital output for conceptualizing temporal relationships between stratigraphic units (s.u.).

This workflow is intended to enable a $4 \mathrm{D}$-aware HBIM that is based on specific semantics and updatable over time. To obtain such a product, it was necessary to work on a double transition both from 2D to 3D representation and from the idea of conservation as a project to one as a process [7]. Great attention was paid to the restitution of Terrestrial Laser Scanning (TLS) data, which turned out to be demanding but fundamental to report and 
map the historical building transformations, thus borrowing a practice that comes from the archaeology of architecture. In this sense, the novelty of the research includes a step forward compared to the traditional "ScanToBIM" process by stressing the optimization of laser scanner data to meet the above-mentioned priority goals in stratigraphic mapping. According to these issues, all recognizable transformations on the architecture masonry as well as their consequent temporal relationships were made three-dimensionally explicit, and the enriched data were embedded in the model itself and not external documents. This option allowed the semi-automatic extraction of the Harris matrix, which is really part of the novelty of the proposed methodology.

\section{State of the Art}

Nowadays, Building Information Modeling (BIM) is at the heart of scientific debate and achieved important milestones, first in the field of new buildings and then in that of existing ones. The implementation of digital informative modeling on historic architecture started more or less ten years ago [8], producing growing scientific literature. Nevertheless, the advantages gained in using HBIM are still accompanied by some criticalities related to the construction of digital models that struggle to represent real complex architectures, as well as to the management of heterogeneous data according to a semantics coherent with all phases and competencies involved in the conservation process [9-11]. This issue derives from the need to control at the same time analytical-scientific investigations, such as historical-documental, metric-morphological, material-constructive, and stratigraphic and degradation studies, but also critical-interpretative ones linked to the understanding of material and immaterial values of architectural heritage, such as its authenticity. Hence the importance both to investigate the transformation of tools for architectural conservation and to experiment with several domain-specific parametric models fit for each of the many activities involved in heritage care strategies [12,13].

In recent years, to avoid such complexity being compromised in the HBIM environment, numerous researches faced the challenge of modeling the uniqueness of historical architectures using parametric software with mostly predefined functionalities [14]. As the literature on the topic points out [15-17], some of these researches dealt with time optimization thanks to ScanToBIM processes [18-20], knowledge modeling through suitable ontologies [21-23], ad hoc libraries by introducing customized parameters for cultural heritage [1], reliable interfaces for connecting HBIM with other databases to be queried [24,25], and also unconventional forms of storytelling [26,27].

In this panorama, the matter of modeling stratigraphic analysis is not yet fully resolved; by stressing this topic, a simultaneous reading of building diachronic transformations can be provided, enabling fundamental keys for knowledge and long-term care activities [28-33]. In longstanding practice, restoration as a discipline borrowed from archaeology the analysis of stratigraphic relationships to investigate and document the transformations of historical architectures. The mutual collaboration between these two disciplines and the consequent knowledge integration demonstrated the role of multidisciplinary contributions in supporting heritage protection, conservation, and enhancement. Recent studies highlighted the potential of HBIM as a tool in which to converge the different objectives, skills, and viewpoints of a multidisciplinary team [31]. Likewise, other researches pointed out the HBIM capability to embed the concept of sustainability by investigating the implementation of a teamwork-HBIM for the sustainable management of architectural heritage; thus, it is a methodology that strengthens the interdisciplinary flow of information, including all disciplines of heritage [34].

With particular reference to conservation, the current state of the art reports the need for the archaeology of architecture to find a new way of summarizing data according to a systemic approach that includes the study of traditional materials and technologies [32]. Besides, the need for sharing archaeological data imposes the inclusion of all documentation components, involving the archives of the stratigraphic excavation, which finds in the Harris matrix the cornerstone of knowledge [35]. Those processes are mainly developed in 
two-dimensional drawings, coming from digital survey data. In the HBIM environment, processes of summarizing and sharing these data can be achieved, on the one hand, by organizing the information contents according to a semantics and taxonomy suitable for the conservation process, and on the other hand, by experimenting with procedures for the automatic representation of the Harris matrix in compliance with codified criteria (e.g., terms and symbols) [36]. Last but not least, the three-dimensional control of all relationships between stratigraphic units opens new scenarios in optimizing laser scanner data: even if some aspects of this topic have already been investigated [37,38], reliable and replicable procedures are required to take full advantage of them in the stratigraphic analysis. Thus, this study aims to tackle these challenges.

If HBIM correctly interprets the logic of cultural heritage, it can ensure an effective conservation project capable of embracing all of its relevant dimensions [2]; within this multidimensional system, modeling time is more essential than ever. As proof of concept, it is worth remembering that the CIDOC Conceptual Reference Model (CRM), which is the reference ontology for cultural heritage, organized information contents according to an "event-centered" logic in which the past is analytically investigated as a succession of discrete events in space and time $[39,40]$.

\section{Materials and Methods}

As the state-of-the-art analysis points out, representing transformation events of historic architecture, while describing temporal relationships between construction components, is still an open issue in heritage modeling. In order to deal with the complexity of this issue, which combines quantitative and qualitative information, this study integrated different methodologies. The first one belongs to the survey of architecture. Thanks to the morphometric study of the building, it is possible to investigate intentional or accidental factors that may have caused a particular volumetric or spatial configuration. This approach highlights the diagnostic potential of the survey activity [41]. The second methodology belongs to the archaeology of architecture. In particular, stratigraphic analysis involves a high degree of critical interpretation of the building based on the inspection of homogeneous units and on the assessment of resulting logical and topological relationships (precedence, succession, superimposition, etc.) [42].

By stressing the functionalities of BIM software, the methodologies proposed here were closely interlinked to build a semantic-enriched model designed as an advanced digital tool to represent and manage the architectural heritage's diachronic development and to support long-term conservation strategies. Furthermore, as heritage activities always involve a wide community of experts from different research domains, this study was targeted to a very specific audience, including architectural historians, archaeologists, and conservation architects. By embracing the logic of BIM linking several disciplines, each of which has its own jargon and toolkit, the research also aimed to shorten the distance between the involved experts, providing them with a $4 \mathrm{D}$-aware HBIM, but also with a procedure for managing it.

The described trial was tested on the Palazzo Ferretti, which is one of the most important architectures in the city of Ancona, housing the National Archaeological Museum of Marche. The study took advantage of a previous research activity carried out by the Department of Construction, Civil Engineering, and Architecture at the Università Politecnica delle Marche. The above activity led to the development of a reality-based model of the palace, starting from the laser scanner survey and aimed at investigating the HBIM potential in defining taxonomies related to the geometrical configurations and rules of classical architecture [43]. Instead, the present study focused on both the Level of Geometry (LoG) and the Level of Information (LoI) an HBIM can guarantee, while highlighting the significant contribution of modeling to heritage conservation activities: modelling is itself a fundamental step for knowledge building and has to be intended as a learning process for architectural preservation. Last but not least, the logic of knowledge 
enrichment has always to be considered as a two-way process, from 2D to $3 \mathrm{D}$ and vice versa.

This case study was selected for the interesting system of stratigraphic traces that have not yet been thoroughly investigated. Palazzo Ferretti is the result of complex transformations that occurred over the centuries. It was built in the 16th century, enlarged and raised in the 18th century, damaged by bombing during the Second World War, and then by earthquakes, and partially rebuilt and subjected to various restoration works.

More specifically, the proposed methodological process was applied to the southwest external façade of the palace; it was based on the following workflow to perform an innovative method that meets the research novelty (Figure 1):

1. Photogrammetric acquisition to support the stratigraphic interpretation of ancient masonries, as well as to test the effectiveness of other survey data, especially highdefinition (HD) laser scanner data. This step was essential both to obtain the most accurate basis for stratigraphic mapping (up to now, photogrammetry is the best one) and to compare its accuracy with that of the HD laser scanner;

2. Modeling and data enrichment to enable the transition from the traditional stratigraphic representation by $2 \mathrm{D}$ views associated with a restoration project to a $3 \mathrm{D}$ stratigraphic mapping for supporting long-term conservation processes;

3. Semi-automatic construction of the Harris matrix to experiment the possibility of visualizing and updating in a semi-automatic way the architectural transformations, as the building changes over time in the face of both new discoveries regarding the past and future modifications;

4. HD laser scanner data optimization in the HBIM environment to investigate the not-secondary role of an HD acquisition in supporting stratigraphic analysis.

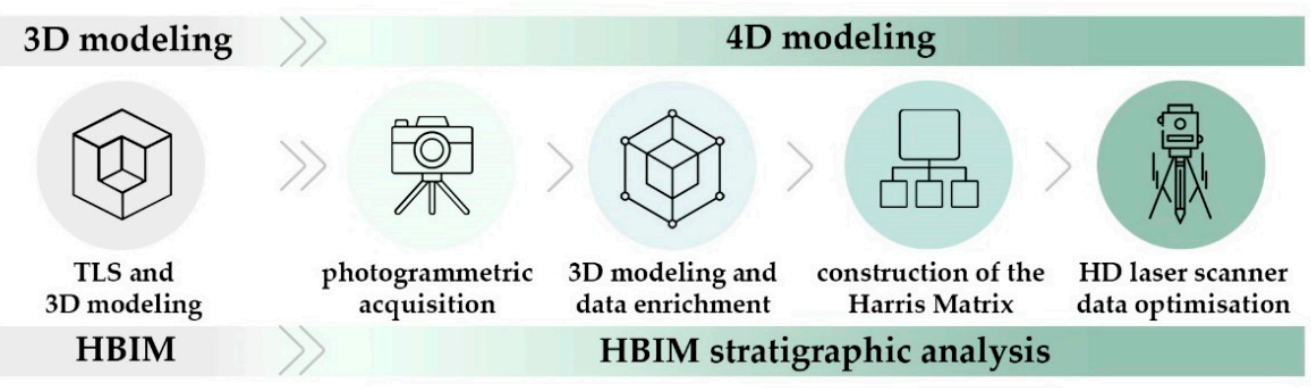

Figure 1. Workflow: HBIM stratigraphic analysis.

In particular, in the proposed workflow the main innovations lie in the second and third steps, as they enable a new form of knowledge representation, boosting the semantic management of 3/4D information and their retrieving and filtering. The entire workflow is intended as a meeting point for domains belonging to different disciplines. Thus, this experimentation also becomes the opportunity to implement a teamwork-HBIM and strengthen the need for interdisciplinarity in cultural heritage activities [34].

\subsection{Photogrammetric Acquisition}

The instrumental acquisition, intended as the optimization of data integration processes, is always the precondition of any conservation activities and, therefore, of any modeling activity that serves this purpose [25].

As already stated, the research took advantage of a laser scanner acquisition of Palazzo Ferretti: a TLS survey including 69 total scans, of which 40 were for the exterior parts of the building and 20 for the interior ones. The resolution of laser scans was $1 \mathrm{~cm}$ at $100 \mathrm{~m}$, with details up to $0.5 \mathrm{~cm}$ at $100 \mathrm{~m}$. The final point cloud was obtained by aligning clouds of all scans consisting of 1.2 billion points with an average absolute error of $1 \mathrm{~mm}$ and a maximum error of $5 \mathrm{~mm}$. Data were processed and recorded in Cyclone software; each station was aligned to obtain a single point cloud, clean of noise and decimated. 
To gain an in-depth understanding of the temporal relationships between the architectural elements of the façade, that point cloud was integrated with the photogrammetric acquisition. The south-west façade of the palace was acquired using two cameras: Sony Alfa 9 full-frame and Sony ILCE 6500 APS-C, each with focal lengths of 50 and $24 \mathrm{~mm}$ and both associated with a tripod or telescopic bar.

The size of the façade (approximately $460 \mathrm{~m}^{2}$ ) made it necessary to divide it into two portions according to a specific photographic project. The used lenses and the calculated sampling distances guaranteed a Ground Sampling Distance (GDS) and, thus, an almost homogeneous resolution. Using two cameras simultaneously, the façade was investigated optimally and expeditiously. The data processing was carried out with Agisoft Metashape software, and divided into four phases: the first phase gave back a sparse cloud starting from the position and orientation of each camera, the second one allowed the generation of the dense cloud, the third one a triangular mesh (with a mesh density based on the number of points calculated in the dense cloud), and the last one a high-resolution orthophoto as the necessary basis for mapping stratigraphic units on the façade (Figure 2).

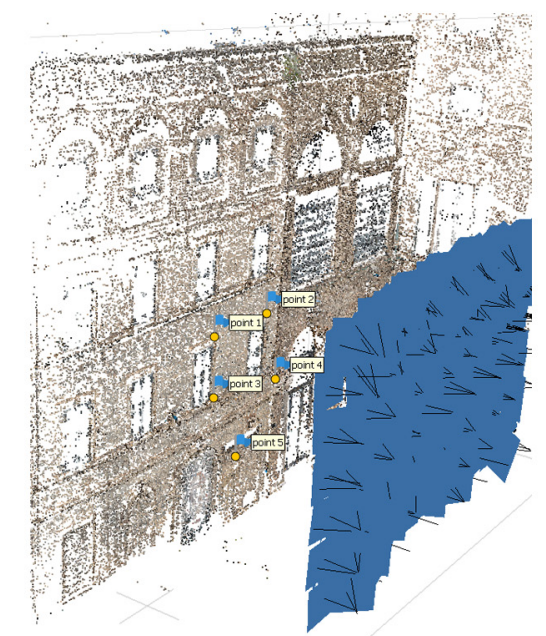

Sparse cloud

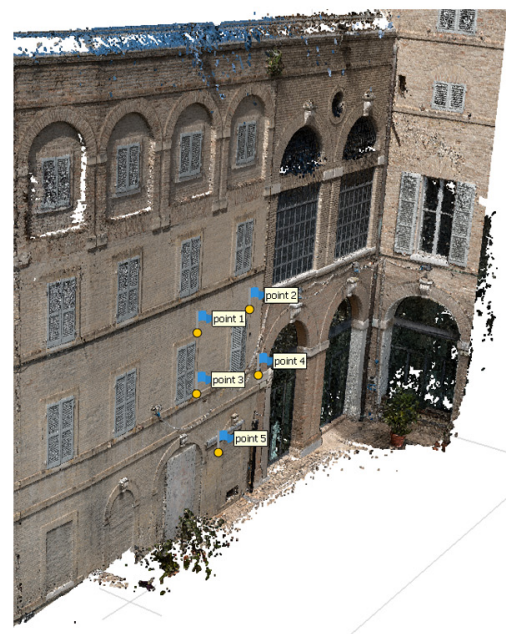

Dense cloud

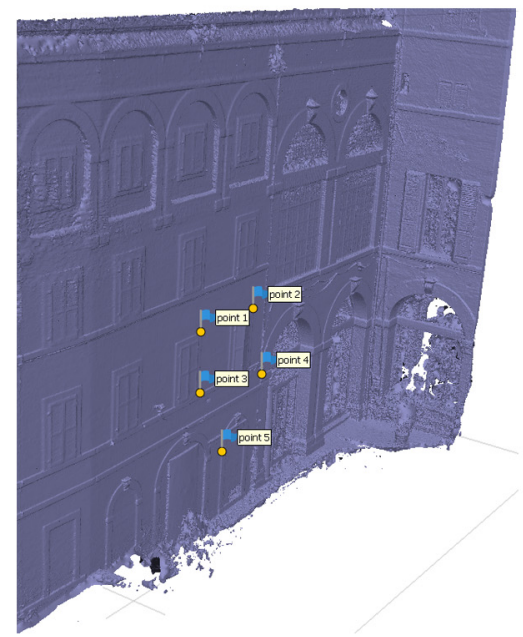

Mesh

Figure 2. Data processing in Metashape.

\subsection{Modeling and Data Enrichment}

The reality-based model of Palazzo Ferretti was developed starting from the laser survey, as described in Section 3.1. Thanks to Autodesk Recap, the point cloud format (.pts) was then converted into .rcp, and all contents were managed using the Revit panel. The façades were modeled and parameterized by creating "system families" for walls, floors, roofs, and marcapianos, while "loadable families" for cornices, portals, and entablatures. For the latter, semantic and geometric constraints were investigated, focusing on the construction practice and the Treaties (Figure 3).

With particular reference to the south-west façade of the palace, a modeling approach coherent with the stratigraphic analysis was investigated, providing the modeling of each unit and sub-unit as basic elements. In this way, the construction of "nested families" was avoided, which would have classified units and sub-units according to other criteria that were not strictly stratigraphic and did not always coincide with these (for example, typological, functional, or construction criteria); moreover, a stratigraphic unit may not coincide with a typological or constructive one. This activity started from a two-dimensional stratigraphic analysis supported by the orthophoto gained through the photogrammetric acquisition, as described in Section 3.1. This process allowed the façade to be ideally divided into stratigraphic units, which are uninterrupted areas. 


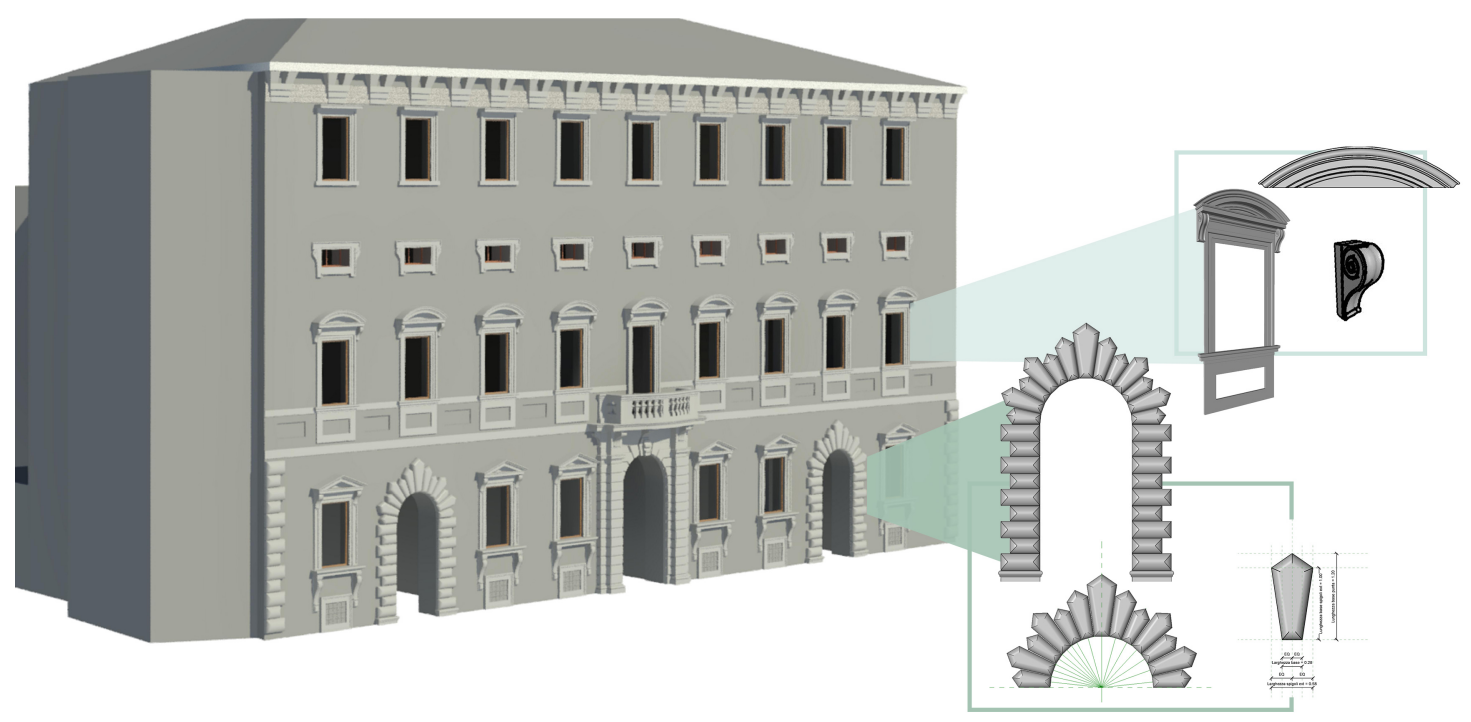

Figure 3. Reality-based model in Revit.

According to main conventions, the units were mapped, progressively numbered, and distinguished into "positive" (describing a single construction intention and designated with a number) and "negative" (presenting signs of material removal and designated with a number inscribed into a square). Then, each unit was characterized from a material and constructional point of view, and the stratigraphic relationships of anteriority, posteriority, and contemporaneity were specified.

These relationships were deduced by checking the interfaces between all units and comparing them with the operational sequences of construction and destruction, as well as with the historical sources. The analysis detected hybrid temporal relationships, that is, relative and absolute, and was based primarily on a direct interpretation of the artefact, which was greatly facilitated because of non-plastered or coated walls. The result allowed the identification of four macro-phases: a late Renaissance phase (phase 1: 1500), an 18thcentury phase (phase 2: 1700), and two phases chronologically successive to the latter, but whose historical time is not yet well-known (phases 3 and 4: post-1700) (Figure 4).
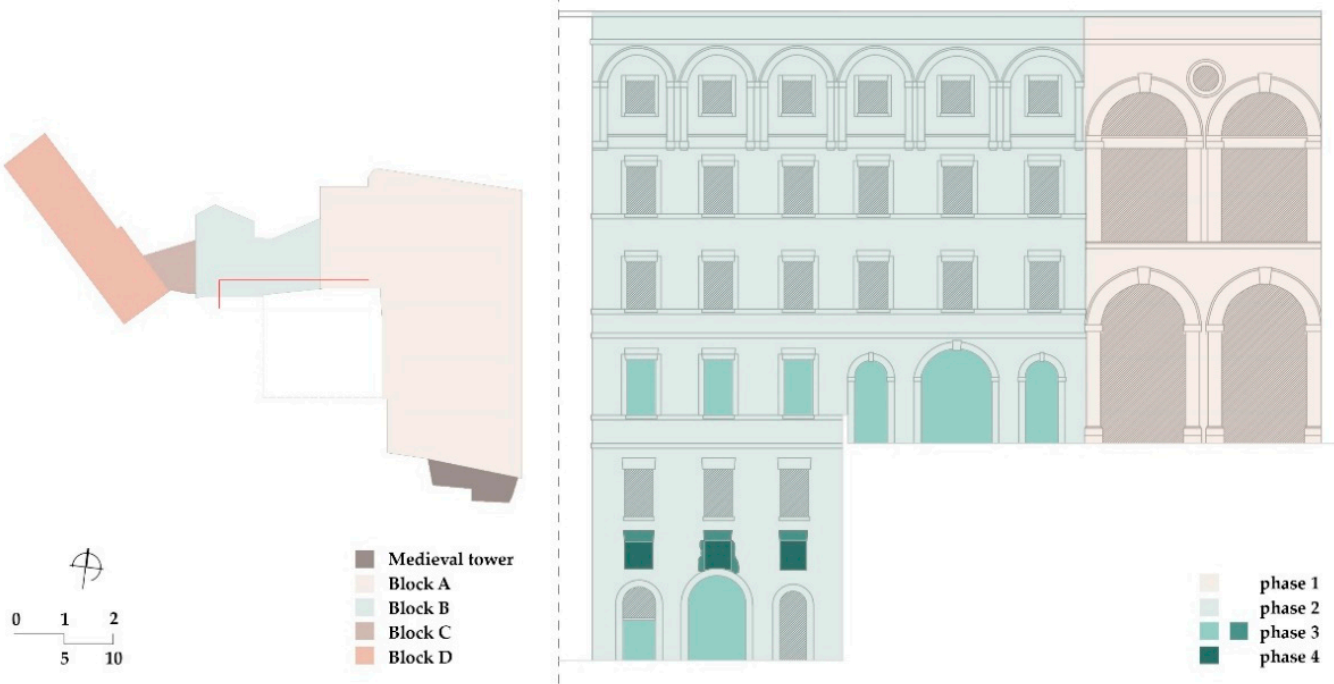

Figure 4. The four temporal macro-phases of Palazzo Ferretti. 
During the modeling phase, parameters created by the properties panel made it possible to organize all the aforementioned information while reflecting the adopted workflow and methodology (Table 1).

Table 1. Implementation of stratigraphic analysis data.

\begin{tabular}{cc}
\hline \multicolumn{1}{c}{ Stratigraphic Analysis Data } \\
\hline ID. & S.u. XX \\
Genesis & Construction_s.u. positive \\
& Demolition_s.u. negative \\
Materials & Brick \\
& Stone \\
& Wood \\
& $\ldots$ \\
Physical consistency & ..g.,: M1: masonry made of reused bricks \\
& (average size x-y-z) with natural hydraulic \\
Dating & lime mortar \\
& Absolute \\
& Relative \\
Phase 1 \\
Construction phase & Phase 2 \\
& Phase 3 \\
Anteriority: & Phase 4 \\
anterior to s.u. & $2,4,5,6,7$, etc. \\
Posteriority: & $6,89,100,45,67$, etc. \\
posterior to s.u. & $6,5,4,34,22$, etc. \\
Contemporaneity: &
\end{tabular}

A sort of "identity card" was drawn out for each stratigraphic unit and sub-stratigraphic unit. Here the following information contents were collected: the identification code of the unit (ID), including the progressive number (e.g., s.u. 1 ; s.u. 1.1), and data describing its origin (genesis), since it is the result of a construction or demolition process and therefore named as "positive" or "negative" units (e.g., construction_s.u. positive).

Additional data concern the materials and the physical consistency of the unit and, finally, the temporal and stratigraphic information, that is, the relative or absolute dating, the construction phase, and relationships of anteriority, posteriority, and contemporaneity.

The latter, instead of providing only descriptive information, explains the relationship linking all modeled units.

In this way, the impossibility of using graphic symbols that conventionally describe the temporal relationships between adjacent stratigraphic units in the 2D drawings was overcome (e.g., triangle: "leans against"; wavy line: "is contemporary with"; broken line: "breaks in relation to"). Furthermore, it was useful for the visualization of each unit to associate "generic model" labels with each element using the "contrassegno" (Figure 5).

All implemented data were then grouped into an abacus, using the "multi-category abacus" tool, which lists all the elements modeled in a Revit project. Thanks to this functionality, the model can be interrogated in its temporal phases according to visualization filters; last but not least, this information can also be exported and imported into other software. By exploiting the above-mentioned tables and their export/import properties, it was also possible to construct the Harris matrix in a semi-automatic way. To achieve this goal, three steps were essential in the modelling and data enrichment phase: modelling each unit and sub-unit, assigning them a unique ID, and making explicit the temporal relations between them, as described above. 


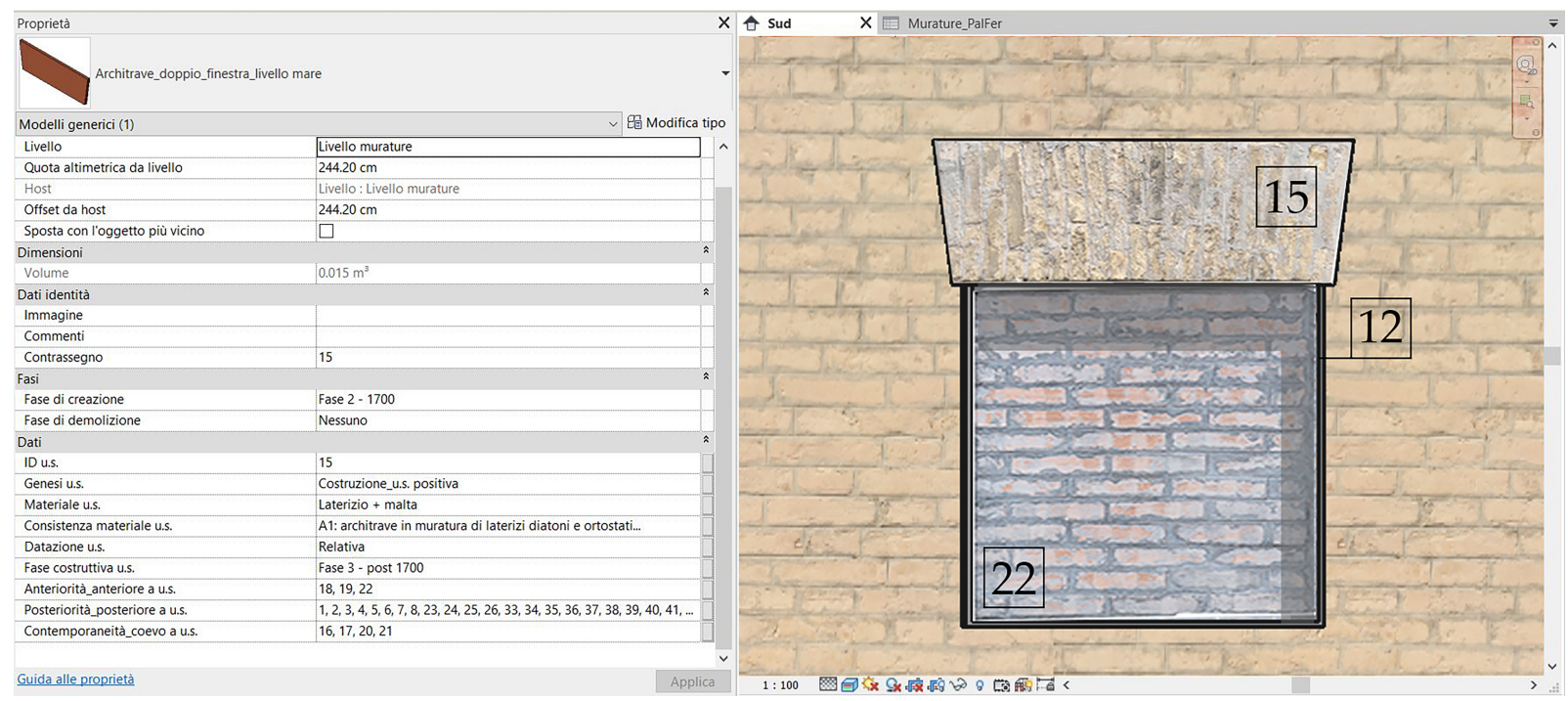

Figure 5. Data enrichment in Revit (e.g., stratigraphic unit 15).

\subsection{Semi-Automatic Construction of the Harris Matrix}

This research phase aimed at enabling a process for the construction of the Harris matrix that would be as automatic as possible and graphically consistent with the wellestablished output, thus easy to share and read for users. Traditionally, the stratigraphic dataset is conceptualized into a diagram or matrix, called a Harris matrix, after the name of the archaeologist who first developed it [44]. This conceptual diagram is a fundamental knowledge tool. Being subject to continuous updates due to discoveries about the past of the building and to transformations that may occur in the future, it would be extremely useful to automate it.

Today, there are some software programs designed for representing the Harris matrix, such as Ad Hoc AM [45], Stratify [46], and Harris Matrix Composer [47]. In this study, some tests were carried out in both Harris Matrix Composer and Stratify. Usually, the first one is not used only to generate a simple stratigraphic diagram, but to model the stratigraphy as a direct acyclic graph and to guide all the interactive processes [35]; despite these advantages, it prevents the import of data from other software. Instead, the second one, Stratify, allows to import Comma-Separated Values (CVS), dBase (DBF), and Paradox (DB) files; thus, its interoperability makes it easier to construct the matrix.

Therefore, data from Revit multi-category databases were imported into Excel, saved in CVS, and then imported into Stratify. Stratify allows one to edit all the units by defining not only its temporal relationships of anteriority, posteriority, and contemporaneity, but its features (e.g., material) and dating, including also a short description (e.g., physical consistency). Once data were imported, it was possible to check for redundant or absent relations, and at the end of the implementation process, the complete diagram with the explicit relations in its final form was displayed (Figure 6).

Harris diagram - Palfer

File Find View Report Preferences Help

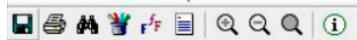

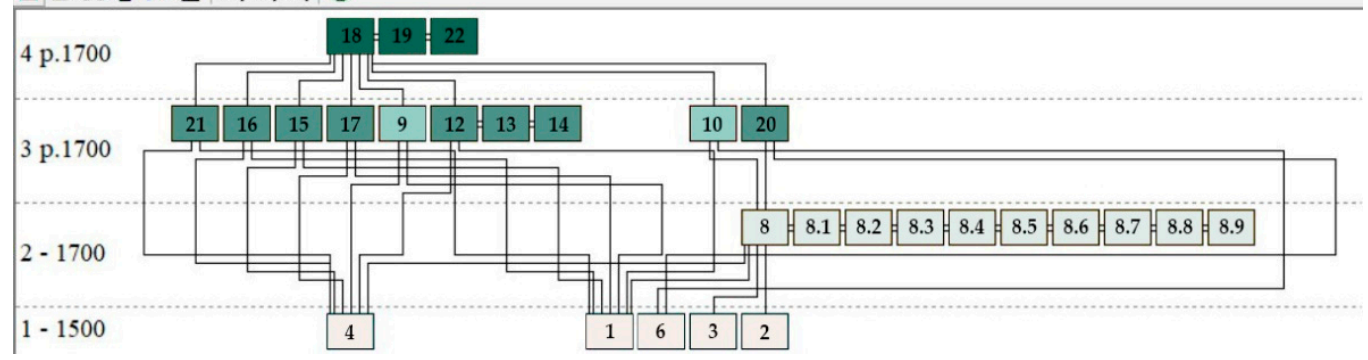

Figure 6. Harris matrix in Stratify. 


\subsection{HD Laser Scanner Data Optimization in the HBIM Environment}

Nowadays, laser scanner technology is the most suitable tool for acquiring data regarding architectural heritage due to the speed in obtaining contents, the accuracy of the information, as well as the suitability for the HBIM workflow. The reliability of semiautomatic modeling from point clouds has been tested with plug-ins or deep learning approaches, but it is not yet sufficiently capable of ensuring recognition processes of some architectural elements directly from surveyed geometries.

Thus, this study tested the optimization of HD laser scanner data as additional contents of the cloud points in the process of interpretation of stratigraphic interfaces. To verify this scenario, an HD scan focused on a single portion of the south-west façade of Palazzo Ferretti was carried out using Leica Geosystems P40 laser scanner. The instrument has an acquisition speed of 1 million points per second, which ensured accuracy and data quality thanks to hybrid technology and automatic data filtering. Two scans were carried out: the first one was for the alignment with the scans already acquired, while the second one was for refining the previous one, including only the wall portion on which the stratigraphic analysis was implemented. The latter was set to an accuracy level of $0.8 \mathrm{~mm}$ at $10 \mathrm{~m}$ to exploit the maximum resolution by the instrument. In the survey stage, no targets were acquired for the alignment of the scans, because the registration phase was managed by the software using cloud-to-cloud algorithms (Iterative Closest Point, ICP) through the intelligent alignment function.

Finally, to prove the feasibility of mapping stratigraphic units directly on the point cloud, spherical panoramas were made using a Sony ILCE 6500 APS-C with a $24 \mathrm{~mm}$ focal length (Figure 7). The achieved data for this portion appear encouraging because the density of HD point cloud allows one to read the masonry texture and single bricks, but the issues and weak points are deeply investigated in the following paragraphs.

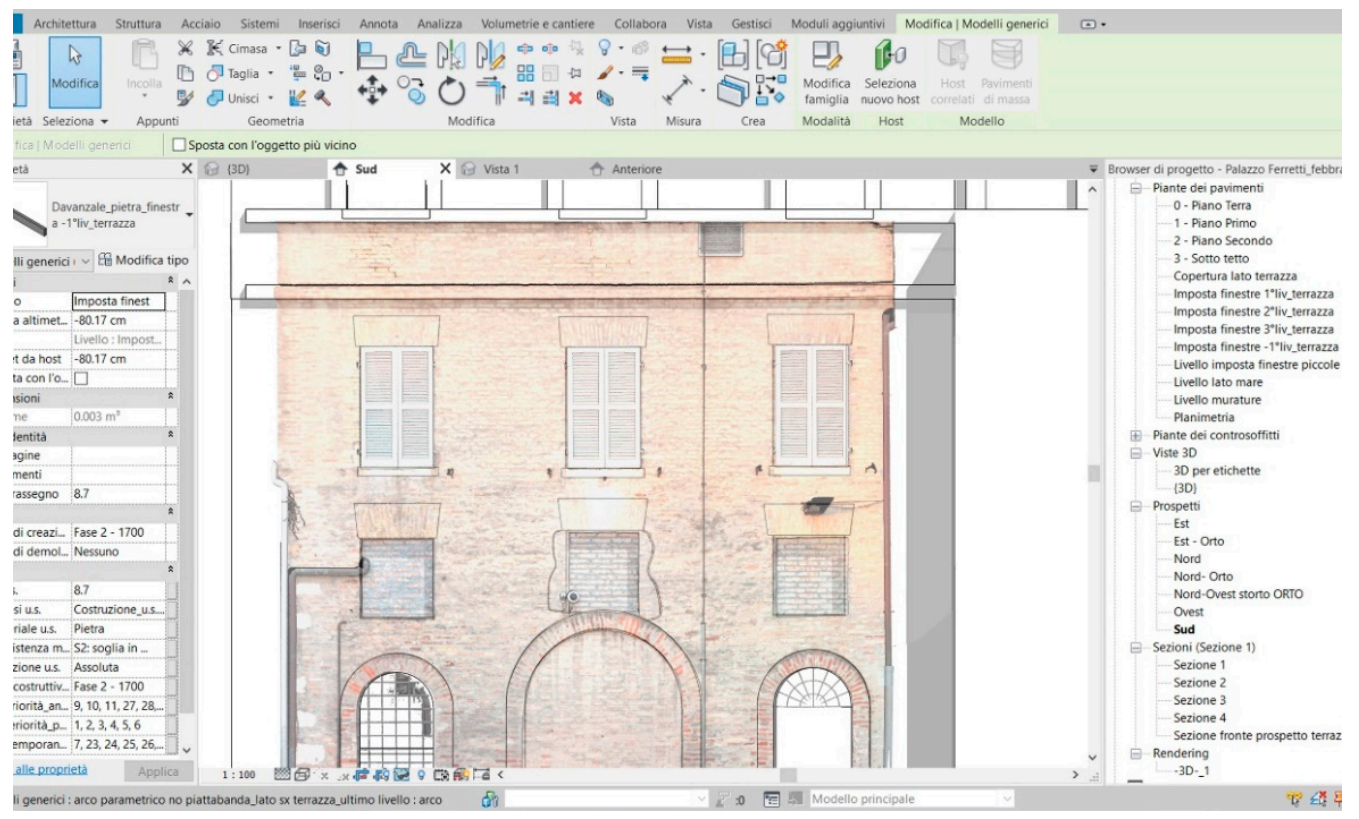

Figure 7. The HD laser scanner acquisition in Revit.

\section{Results}

This research took advantage of HBIM capability in modeling the fourth dimension of architectural heritage and highlighted its potential and limits as an enabling tool for long-term processes of conservation and sustainable management.

In the scientific chain that has long involved the discipline of restoration adopting stratigraphic analysis from archaeology, multi-level benefits arising from HBIM were detected in the accurate and integrated control of metric, geometric, material, technological, 
and chronological data of historic buildings, as well as in the possibility of automating some graphic outputs.

First of all, the applied methodology demonstrated the importance of modelling stratigraphic units one by one, enriching them with information contents based on semantics consistent with conservation activities. Secondly, the need to model each unit individually was combined with the need to make explicit the temporal relations between them (anteriority, posteriority, contemporaneity) for semi-automating the construction of the Harris matrix using open-source software.

Although this study proposed an HBIM environment in which 2D views obtained from the model were devoid of the graphic symbols enriching traditionally stratigraphic drawings, in any case, users and professionals were aware of this information via the properties, these being the core of practice in BIM. The adopted tool for this functionality, that is, the label families for annotations, allowed the implementation of the information regarding "positive" or "negative" stratigraphic units according to the conventional graphic code, while graphic symbols describing the temporal relationships were implemented as project parameters using text strings. Moreover, this partial limit was overcome just by testing a demo for the semi-automation of the Harris matrix that conceptually summarizes all temporal relations and can be continuously updated. This output was time-consuming in the first phase of enriching the stratigraphic relations, but in the long-term perspective, it was justified by the speed of its updating and the good quality of its graphic design. Similar considerations are invariant for all BIM approaches, and it has already demonstrated the convenience of embracing a change of mind to take advantage of the full potentials of this digital tool.

Another result that is worth mentioning was the validation of a digital documentation workflow that boosted the concept of the HBIM as a centralized data collector strictly linked with different experts' knowledge. In particular, the model workflow is suitable for conservation experts that are facilitated to exploit and manage high-quality threedimensional data, coming from TLS or photogrammetry, that are usually the prerogative of survey experts. In this light, further data collections could facilitate the creation of digital twins for architectural heritage, incorporating reliable information about geometry and surface changes that are easily updatable.

The analysis of the cultural background and state of the art on the implementation of stratigraphic analysis in the HBIM environment revealed a problem statement that was mainly founded on a knowledge gap in creating and querying $4 \mathrm{D}$-aware models. The novelty of this research focused on testing an enabling workflow for supporting the stepby-step transformation of heritage tools from $2 \mathrm{D}$ to $3 \mathrm{D}$ representation and the construction of a kind of knowledge representation required by the planned conservation vision.

\section{Discussion}

The research also pointed out some critical issues of the tested solutions and opened up future works.

The HD laser scanner acquisition was aimed at optimizing the stratigraphic analysis, but it turned out to be very time-consuming. As is well-known, the laser scanner is an excellent instrument for surveys to perform very quickly (e.g., data acquisition for buildings damaged by natural disasters). An exhaustive stratigraphic mapping based only on data from HD laser scanner acquisitions is therefore not yet fully feasible, because the time for analyzing data increases enormously with the size of the survey subject. Although the graininess of the laser data could cause some problems in features identification, the information recorded by the scanner is very comprehensive from a quantitative point of view, and the results are qualitatively comparable with the photogrammetric data (Figure 8). Considering these remarks, the HD laser acquisition is nevertheless a useful additional tool for the interpretation of stratigraphic units. Moving from a traditional 2D representation to a 3D one, the stratigraphic units acquire a more realistic dimension; in this way, modelling becomes not only a phase of data representation, but a phase of continuous 
analysis and questioning of transformation processes of the artefact over time. Therefore, this work strongly emphasizes the diagnostic value of the survey, and the cognitive value of modelling, as well as its contribution to the critical-interpretative analysis of architectural heritage. New studies can be conducted in this direction aimed at increasingly integrating laser data into the stratigraphic mapping of ancient facades.
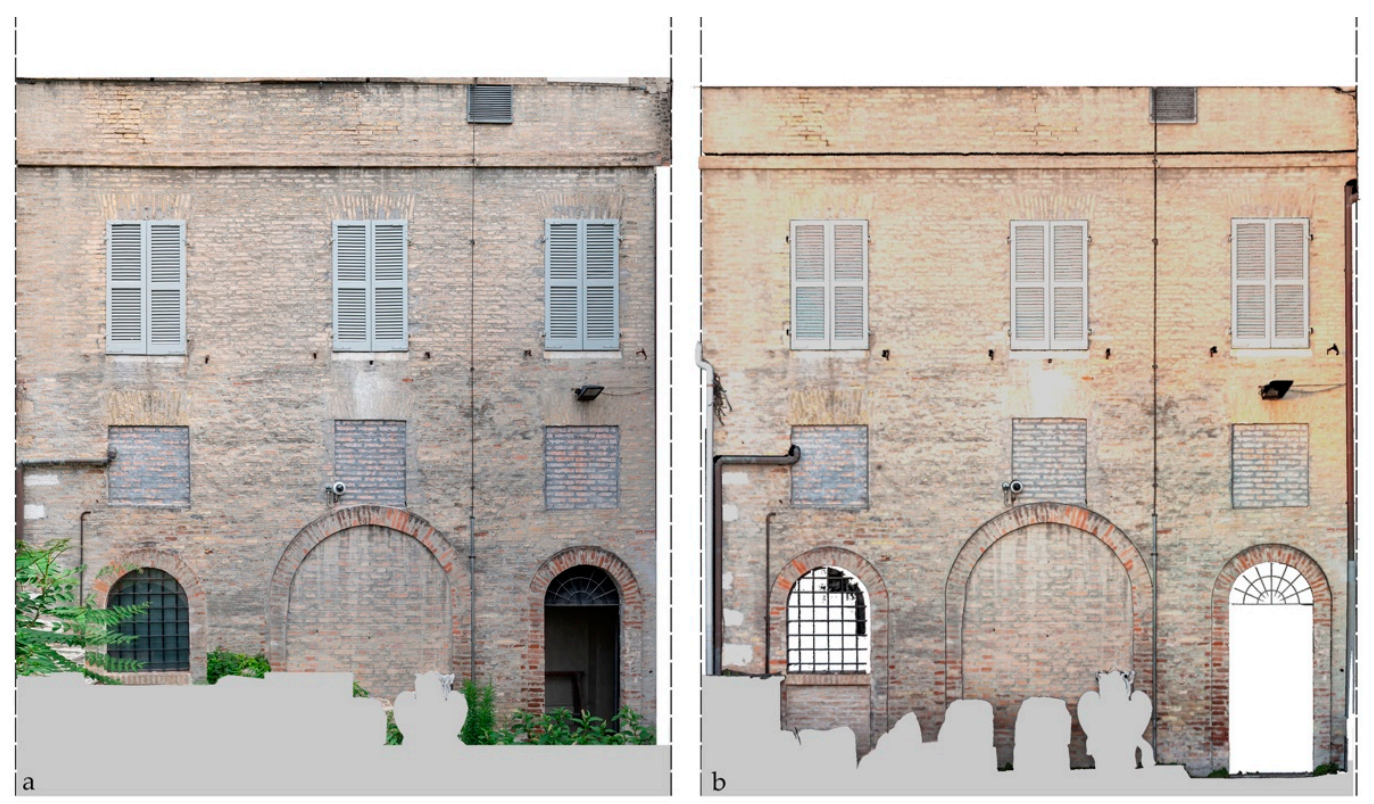

Figure 8. Comparison between the orthophoto (a) and HD laser acquisition (b).

In addition, future works will involve other HBIM models with the same method according to the archaeology of architecture discipline, to test the workflow and stress the comparison of the used ontologies and knowledge representation.

Regarding the objective of knowledge sharing, the HBIM potential in the dissemination of information for non-expert users, as well as construction industry experts, is not fully exploited. In this light, the authors are planning to develop new functionalities and special features, to interact with the diachronic description of the building. For this reason, the most recent techniques for developing virtual environments will be investigated. There are some studies [27] that have been developed on immersive and virtual experiences in models coming from the BIM environment, but weak points are already agreed on, such as the level of interoperability between the HBIM model and new levels of built heritage virtualization. The first challenge will be to conserve the data enrichment and the semantics and hierarchical levels of information achieved in the HBIM environment and to create effective and usable virtual experiences also for the general public. Main problems, indeed, come from the vocabulary and the lack of standard definitions in data enrichment, and also in translation from an expert domain to a storytelling level, in which the 4D HBIM should be a key point for the visualization of non-existing parts and, in general, for the virtual anastylosis processes.

Another challenge to be faced will be the automation or facilitation of the phase through a dedicated tool, taking advantage of the survey data but also of previous tested plugins or research based on Visual Program Languages (VPL) such as Dynamo or Grasshopper.

Finally, modeling the chronological sequences of historic buildings contributes to affirming the physical and material authenticity of heritage and, at the same time, allows increased control of transformations by evaluating the risk and vulnerability thanks to the study of all stratigraphic interfaces and discontinuities. Moreover, this process provides an interesting framework for planning medium- to long-term conservation strategies for architecture marked by complex and diachronic development. All of the above follow an idea 
of conservation of architectural heritage that mainly means managing its transformations over time [48]. Thus, the proposed research chain enabled a 4D-aware HBIM, based on high-quality morphometric acquisitions and critical analysis framed by both digitization of heritage and the archaeology of architecture.

Author Contributions: Conceptualization, C.M. and R.Q.; methodology, R.M.; validation, C.M.; investigation, C.M.; writing - original draft preparation, C.M. and R.M.; writing-review and editing, R.Q.; visualization, R.M. In particular: 1.1 Cultural background [C.M.], 1.2. Assumption and aim [R.Q], 2. State of the Art [C.M., R.Q., R.M.], 3 Materials and Methods [C.M.], 3.1. Photogrammetric acquisition [R.M.], 3.2. Modeling and data enrichment [C.M., R.M.], 3.3. Semi-automatic construction of Harris Matrix [R.M], 3.4. HD laser scanner data optimization in HBIM environment [R.Q., R.M.], 4. Results [C.M., R.Q., R.M.], 5. Discussion [R.Q.]. All authors have read and agreed to the published version of the manuscript.

Funding: This research received no external funding and is part of the strategic project of Università Politecnica delle Marche "CIVITAS-ChaIn for excellence of reflectiVe societies to exploit dIgital culTural heritAge and museumS".

Institutional Review Board Statement: Not applicable.

Informed Consent Statement: Not applicable.

Data Availability Statement: The data presented in this study are available on request from the corresponding author. The data are not publicly available as they are property of the Regional Directorate of Museums of Marche-National Archaeological Museum of Marche.

Acknowledgments: The survey activities were authorized by the concession of MiBACT, Ministry of Heritage and Cultural Activities and Tourism-Regional Directorate for Museums of Marche Region. The elaborations produced are property of the Regional Directorate of Museums of Marche-National Archaeological Museum of Marche. Thanks to the Director of the National Archaeological Museum, Nicoletta Frappiccini, and to the Director of the Regional Museum Directorate, Luigi Gallo, for hospitality and for enabling access to the museum. Thanks to Paolo Clini (DICEA, Department of Civil, Building, Engineering, and Architecture of Polytechnic University of Marche), as the scientist responsible for Palazzo Ferretti surveys, and to Floriano Capponi and Gianni Plescia, as the technicians that carried out the field campaign.

Conflicts of Interest: The authors declare no conflict of interest.

\section{References}

1. Castellano-Román, M.; Pinto-Puerto, F. Dimensions and Levels of Knowledge in Heritage Building Information Modelling, HBIM: The model of the Charterhouse of Jerez (Cádiz, Spain). Digit. Appl. Archaeol. Cult. Herit. 2019, 14, e00110. [CrossRef]

2. UNI Ente Italiano di Normazione. Available online: https:/ / www.uni.com (accessed on 20 January 2021).

3. Fiorani, D.; Acierno, M. Conservation process model (CPM): A twofold scientific research scope in the information modelling for cultural heritage. ISPRS J. Photogramm. Remote Sens. 2017, XLII-5/W1, 283-290. [CrossRef]

4. Australia ICOMOS. The Australia ICOMOS Charter for Places of Cultural Significance, Burra Chart; Australia ICOMOS Incorporated: Burra, Australia, 2013.

5. UNESCO; ICCROM; ICOMOS; IUCN. Managing Cultural World Heritage; Unesco World Heritage Center: Paris, France, 2013; ISBN 978-92-3-001223-6.

6. UNESCO; ICCROM; ICOMOS; IUCN. Managing Disaster Risks for World Heritage; Unesco World Heritage Center: Paris, France, 2010; ISBN 978-92-3-104165-5.

7. Della Torre, S.; Pili, A. Built Heritage Information Modelling/Management. Research Perspectives. In Digital Transformation of the Design, Construction and Management Processes of the Built Environment; Daniotti, B., Gianinetto, M., Della Torre, S., Eds.; Springer Nature: Cham, Switzerland, 2020; pp. 231-241. [CrossRef]

8. Murphy, M.; Mcgovern, E.; Pavia, S. Historic building information modelling (HBIM). Struct. Surv. 2009, 27. [CrossRef]

9. Murphy, M.; McGovern, E.; Pavia, S. Historic Building Information Modelling-Adding intelligence to laser and image based surveys of European classical architecture. ISPRS J. Photogramm. Remote Sens. 2013, 76, 89-102. [CrossRef]

10. Simeone, D.; Cursi, S.; Acierno, M. BIM semantic-enrichment for built heritage representation. Autom. Constr. 2019, 97, 122-137. [CrossRef]

11. López, F.J.; Lerones, P.M.; Llamas, J.; Gómez-Garcia-Bermejo, J.; Zalama, E. Linking HBIM graphical and semantic information through the Getty AAT: Practical application to the Castle of Torrelobatón. In IOP Conference Series: Materials Science and Engineering; IOP Publishing Ltd.: Florence, Italy, 2018. 
12. Daniotti, B.; Gianinetto, M. Management Stage. Introduction. In Digital Transformation of the Design, Construction and Management Processes of the Built Environment; Daniotti, B., Gianinetto, M., Della Torre, S., Eds.; Springer Nature: Cham, Switzerland, 2020; pp. 229-230. [CrossRef]

13. Fiorani, D.; Acierno, M.; Cutarelli, S.; Donatelli, A. Transformation of tools and conservation of architecture. Some researches on the use of digital systems for the intervention on the historical buildings. Épités-Épitészettudomány 2020, 49, 97-131. [CrossRef]

14. Della Torre, S. Un bilancio del progetto BHIMM. In Modellazione e Gestione delle Informazioni per il Patrimonio Edilizio Esistente; Della Torre, S., Ed.; INGENIO-WEB. Available online: https: / / core.ac.uk/download/pdf/154335514.pdf (accessed on 20 January 2021).

15. Dore, C.; Murphy, M. Current state of the art historic building information modelling. ISPRS J. Photogramm. Remote Sens. 2017, 42, 185-192. [CrossRef]

16. López, F.J.; Lerones, P.M.; Llamas, J.; Gómez-García-Bermejo, J.; Zalama, E. A Review of Heritage Building Information Modeling (H-BIM). Multimodal Technol. Interact. 2018, 2, 21. [CrossRef]

17. Tobiasz, A.; Markiewicz, J.; Lapinski, S.; Nikel, J.; Kot, P.; Muradov, M. Review of Methods for Documentation, Management, and Sustainability of Cultural Heritage. Case Study: Museum of King Jan III's Palace at Wilanów. Sustainability 2019, 11, 7046. [CrossRef]

18. Quattrini, R.; Malinverni, E.S.; Clini, P.; Nespeca, R.; Orlietti, E. From TLS to HBIM. high quality semantically-aware 3d modeling of complex architecture. ISPRS J. Photogramm. Remote Sens. 2015, XL-5/W4, 367-374. [CrossRef]

19. Apollonio, F.I.; Gaiani, M.; Sun, Z. A Reality Integrated BIM for Architectural Heritage Conservation. In Handbook of Research on Emerging Technologies for Architectural and Archaeological Heritage; IGI Global: Hershey, PA, USA, 2017; pp. 31-36.

20. Brumana, R.; Oreni, D.; Barazzetti, L.; Cuca, B.; Previtali, M.; Banfi, F. Survey and Scan to BIM Model for the Knowledge of Built Heritage and the Management of Conservation Activities. In Digital Transformation of the Design, Construction and Management Processes of the Built Environment; Daniotti, B., Gianinetto, M., Della Torre, S., Eds.; Springer Nature: Cham, Switzerland, 2020; pp. 391-400. [CrossRef]

21. Acierno, M.; Cursi, S.; Simeone, D.; Fiorani, D. Architectural heritage knowledge modelling: An ontology-based framework for conservation process. J. Cult. Herit. 2017, 24, 124-133. [CrossRef]

22. Di Giulio, R.; Maietti, F.; Piaia, E. 3D documentation and semantic aware representation of Cultural Heritage: The INCEPTION project. In Proceedings of the 2016 Eurographics Workshop on Graphics and Cultural Heritage, Genova, Italy, 5-7 October 2016.

23. Gargaro, S.; Del Giudice, M.; Ruffino, P.A. Towards a multi-functional HBIM model. SCIRES-IT 2018, 8, 49-58. [CrossRef]

24. Bruno, N.; Roncella, R. HBIM for conservation: A new proposal for information modeling. Remote Sens. 2019, 11, 1751. [CrossRef]

25. Inzerillo, L.; Turco, M.L.; Parrinello, S.; Santagati, C.; Valenti, G.M. Bim and architectural heritage: Towards an operational methodology for the knowledge and the management of cultural heritage. Disegnarecon 2016, 9, 1-9.

26. Maietti, F.; Di Giulio, R.; Piaia, E.; Medici, M.; Ferrari, F. Enhancing Heritage fruition through 3D semantic modelling and digital tools: The INCEPTION project. In IOP Conference Series: Materials Science and Engineering; IOP Publishing Ltd.: Florence, Italy.

27. Banfi, F.; Oreni, D. Virtual Reality (VR), Augmented Reality (AR), and Historic Building Information Modeling (HBIM) for Built Heritage Enhancement. In Impact of Industry 4.0 on Architecture and Cultural Heritage; IGI Global: Hershey, PA, USA, 2020; pp. 111-136.

28. Santoni, A.; Martín-Talaverano, R.; Quattrini, R.; Murillo-Fragero, J.I. HBIM approach to implement the historical and constructive knowledge. The case of the Real Colegiata of San Isidoro (León, Spain). Virtual Archaeol. Rev. 2021, 12, 49-65. [CrossRef]

29. Brusaporci, S.; Ruggeri, G.; Maiezza, P.; Tata, A. AHBIM per l'analisi stratigrafica dell'architettura storica. Restauro Archeol. 2018, 27, 112-131. [CrossRef]

30. Spallone, R.; Piano, A.; Piano, S. BIM e beni architettonici: Analisi e rappresentazione multiscalare e multidimensionale di un insediamento storico. Il caso studio di Montemagno, Borgo Nuovo piemontese. Disegnarecon 2016, 16, 1-13.

31. Trizio, I.; Savini, F.; Giannangeli, A.; Boccabella, R.; Petrucci, G. The archaeological analysis of masonry for the restoration project in HBIM. ISPRS J. Photogramm. Remote Sens. 2019, XLII-2/W9, 715-722. [CrossRef]

32. Pittaluga, D.; Di Rocco, A.; Casagrande, C.; Guerinoni, S.; Pellegri, G. Historical earthen walls: From knowledge to conscious conservation. ISPRS J. Photogramm. Remote Sens. 2020, 44, 1117-1124. [CrossRef]

33. Trizio, I. Indagini Stratigrafiche e Sistemi Informativi Architettonici: Il GIS della chiesa di S. Maria in Valle Porclaneta. Arqueol. Arquit. 2009, 6, 93-113. [CrossRef]

34. Nieto-Julián, J.E.; Lara, L.; Moyano, J. Implementation of a TeamWork-HBIM for the Management and Sustainability of Architectural Heritage. Sustainability 2021, 13, 2161. [CrossRef]

35. Costa, S. Una proposta di standard per l'archiviazione e la condivisione di dati stratigrafici. Archeol. Calc. $2019,30,459-462$.

36. Borin, P.; Bernardello, R.A.; Grigoletto, A. Connecting Historical Information with BIM Ontologies. HBIM Methods for the Visualization of Harris Matrix for the Torrione in Carpi. In Graphical Heritage, Springer Series in Design and Innovation; Springer: Cham, Switzerland, 2020; Volume 5.

37. Matrone, F. Modello HBIM da nuvola di punti: La verifica metrica dei dati e la validazione dei risultati. Boll. SIFET 2018, 2, 48-56.

38. Di Luggo, A.; Scandurra, S. The knowledge of the architectural heritage in hbim systems from the discrete model to the parametric model. Disegnarecon 2016, 9, 1-8.

39. Biagetti, M.T. An ontological model for the integration of cultural heritage information: CIDOC-CRM. JLIS. It 2016, 7, 43-77. 
40. Doerr, M.; Bruseker, G.; Bekiari, C.; Ore, C.E.; Velios, T.; Stead, S. Definition of the CIDOC Conceptual Reference Model. Produced by the ICOM/CIDOC Documentation Standards Group, Continued by the CIDOC CRM Special Interest Group; CIDOC-CRM. Available online: http:/ / www.cidoc-crm.org/sites/default/files/2018-10-26\%23CIDOC\%20CRM_v6.2.4_esIP.pdf (accessed on 20 January 2021).

41. Torsello, P.B. La Materia del Restauro. Tecniche e Teorie Analitiche; Marsilio: Venezia, Italy, 1988.

42. Musso, S.F. Recupero e Restauro Degli Edifici Storici. Guida Pratica al Rilievo e Alla Diagnostica; EPC Libri: Roma, Italy, 2016.

43. Moreira, A.; Quattrini, R.; Maggiolo, G.; Mammoli, R. Hbim methodology as a bridge between Italy and Argentina. ISPRS J. Photogramm. Remote Sens. 2018, 42, 715-722. [CrossRef]

44. Harris, E.C. Principi di Stratigrafia Archeologica; NIS, La nuova Italia Scientifica: Roma, Italy, 1983.

45. Ad Hoc, A.M. Available online: https://www.adhoc3d.com/software/adhocam.php (accessed on 20 January 2021).

46. Stratify 1.5. Available online: http:/ / www.stratify.org/ (accessed on 20 January 2021).

47. Harris Matrix Composer. Available online: https:/ / harrismatrixcomposer.com/\#/ (accessed on 20 January 2021).

48. Della Torre, S. Dall'equilibrio al divenire. Strumenti e tecniche per il coordinamento e la programmazione delle attività conservative. In Tecniche di Restauro. Aggiornamento; UTET: Torino, Italy, 2013; pp. 303-317. 